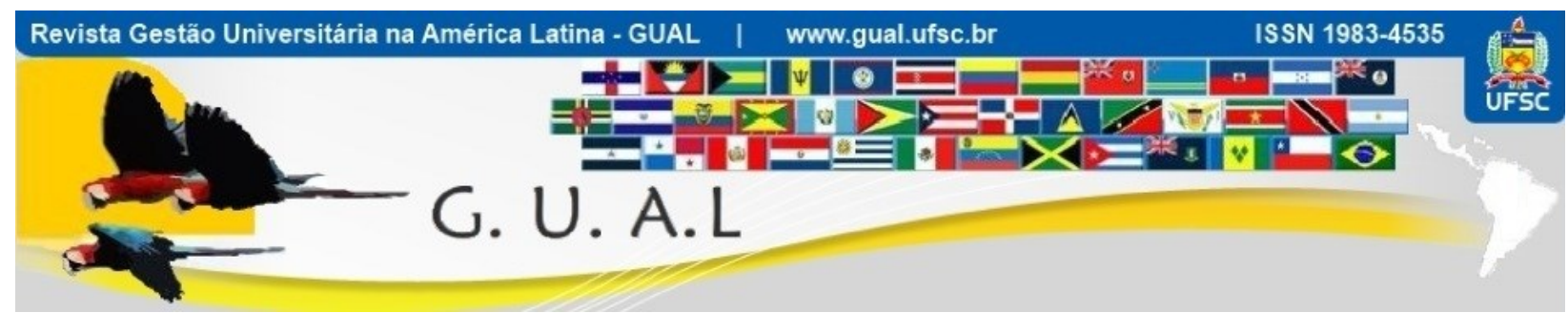

DOI: http://dx.doi.org/10.5007/1983-4535.2017v10n4p269

\title{
PERCEPÇÃO DAS CONTRIBUIÇÕES DA FORMAÇÃO EM GESTÃO EM SAÚDE DO PNAP A PARTIR DA VISÃO DE EGRESSOS: UMA AVALIAÇÃO NEGOCIADA E CONTEXTUALIZADA
}

\author{
PERPECTION OF THE CONTRIBUTIONS OF THE TRAINING IN HEALTH \\ MANAGEMENT OF THE PNAP FROM THE GRADUATES VISION: A \\ NEGOTIATED AND CONTEXTUALIZED EVALUATION
}

Luzia Coelho Rodrigues, Mestre Universidade Federal do Vale do São Francisco - UNIVASF luzia.coelho@univasf.edu.br

Roberto Brazileiro Paixão, Doutor Universidade Federal da Bahia - UFBA robertobrazileiro@gmail.com

Francisco Ricardo Duarte, Doutor Universidade Federal do Vale do São Francisco - UNIVASF frduarte0@gmail.com

Recebido em 25/novembro/2016

Aprovado em 16/outubro/2017

Sistema de Avaliação: Double Blind Review

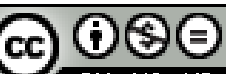

Esta obra está sob uma Licença Creative Commons Atribuição-Uso. 


\title{
RESUMO
}

O estudo avaliativo teve o objetivo de identificar, a partir da percepção de egressos, as contribuições do curso de especialização em Gestão em Saúde do PNAP/UNIVASF para a melhoria das práticas de gestão, utilizando-se da abordagem negociada e contextualizada. As informações foram obtidas por meio de grupos focais e foram interpretadas através da análise do discurso do sujeito coletivo. A abordagem pluralista possibilitou a identificação, a partir do envolvimento de grupos de egressos, de aspectos da avaliação de curso que foram priorizados pelos participantes, bem como a consequente contribuição desses aspectos para a prática profissional. Os discursos-síntese formados representam as perspectivas de egressos sobre indicadores do processo avaliativo a partir das necessidades de múltiplos atores e interessados no programa educacional. Resultados contribuem para a reflexão sobre práticas avaliativas com a utilização de pluralidade de ideias aplicáveis à avaliação universitária, instigando questões que poderão ser aprofundadas em estudos futuros com egresso.

Palavras-chave: Avaliação Educacional. Programa PNAP. Egressos. Avaliação negociada.

\begin{abstract}
The objective of the evaluative study was to identify the contributions of the specialization course in Health Management from the PNAP / UNIVASF for the improvement of management practices, using the negotiated and contextualized approach. The information obtained through focus groups were interpreted through the analysis of the collective subject discourse. The pluralistic approach was possible to identify aspects of the course evaluation, prioritized by the participants, and the consequent contribution of these aspects to the professional practice. The syntheses formed represent the perspectives of graduates on indicators of the evaluation process from of the needs of multiple actors and interested in the educational program. The results contribute to the reflection on evaluative practices with the use of plurality of ideas applicable to the university evaluation, instigating questions that could be deepened in future studies with graduates.
\end{abstract}

Keywords: Educational Evaluation. PNAP Program. Graduates. Negotiated Evaluation. 


\section{INTRODUÇÃO}

Os resultados do presente estudo fazem parte de uma pesquisa com egressos do Programa de Formação em Administração Pública (PNAP), denominada Expectativas e Perspectivas da avaliação de Cursos a partir de seus Egressos. Para a construção do estudo avaliativo, buscou-se uma abordagem avaliativa que possibilitasse a participação de grupos de interesses no objeto em avaliação, bem como a inclusão da negociação na coleta de informações sobre a avaliação do curso. O referencial construtivista foi adotado para a identificação das contribuições da formação em Gestão em Saúde, ofertada pela Universidade Federal do Vale do São Francisco (UNIVASF), através da Secretaria de Educação a Distância (Sead), unidade organizacional responsável pela oferta do curso.

O acompanhamento de egressos vem despertando interesse de pesquisadores há algum tempo. Conforme os estudos de Paul (2015), as primeiras pesquisas longitudinais tiveram início na década de 1960 nos Estados Unidos, mas com registros de estudos ocasionais desde 1930; na França, a partir de 1970, e no Brasil surgiram pesquisas em 1980 (MACHADO, 2010). Surgiram portais de egressos, a maioria deles limitando-se a informações cadastrais (PAUL, 2015), havendo, portanto, a necessidade de priorizar a avaliação de impactos e do processo na avaliação de políticas educacionais (FERREIRA; TENÓRIO, 2010).

Seguindo o princípio da negociação, priorizou-se neste estudo a participação do egresso em relação aos aspectos considerados importantes na avaliação do curso realizado e a consequente contribuição desses aspectos para a prática profissional. O objetivo foi identificar, a partir da percepção dos egressos dos diversos polos de apoio presencial, as contribuições do curso de especialização em Gestão em Saúde do PNAP/UNIVASF, utilizando-se da abordagem negociada e contextualizada proposta por Guba e Lincoln (1989).

A partir da revisão da literatura sobre avaliação de programas educacionais, observouse a existência de diversas abordagens avaliativas (WORTHEN; SANDERS; FITZPATRICK, 2004), sendo que as com enfoques pluralistas permitem aprofundar os processos avaliativos, enfatizando as preocupações e os problemas de determinado grupo, proporcionando a avaliação educacional responsiva defendia por Stake (1972).

O processo da avaliação responsiva é "interativo e negociado" e inclui a identificação de diferentes visões entre grupos de interesse e as respostas a essas questões por meio da coleta de informações, avaliação conduzida pelo método construtivista (GUBA; LINCOLN, 
1989, p.47-48), ou seja, o foco responsivo e a metodologia construtivista são os principais elementos da avaliação negociada proposta pelos autores.

Registra-se que o PNAP é um programa em rede nacional com oferta por meio do Sistema Universidade Aberta do Brasil (UAB). O curso pesquisado tem como objetivo qualificar gestores para atuação junto às políticas de saúde no âmbito das esferas federal, estadual e municipal. Nessa perspectiva, são muitos os que podem ser afetados pelo programa ou por sua avaliação (WORTHEN; SANDERS; FITZPATRICK, 2004), a exemplo dos grupos de interessados constituídos por gestores, discentes, egressos, tutores, docentes, equipe multidisciplinar, coordenadores de polos de apoio presencial, financiadores (Capes/MEC) e sociedade em geral. Cada grupo desses pode ter uma visão diferente do programa e expectativas diferentes em relação ao PNAP e à avaliação dos seus cursos.

Tendo em vista as implicações políticas e o propósito da avaliação, foram considerados, inicialmente, os interesses dos gestores da Educação a Distância (EAD) no âmbito da instituição pesquisada, o que foi visto em sondagens através de pesquisa exploratória prévia com gestores da Sead, com a coordenação da Comissão Própria de Avaliação (CPA) e com responsável pela Procuradoria Institucional, os quais apresentaram as seguintes reivindicações, preocupações e questões:

a) Não há avaliações formalizadas na instituição para os cursos de especialização, uma vez que o MEC/CAPES ainda não regulamentou essa prática. No entanto, o acompanhamento da inserção dos egressos no mercado de trabalho constitui fonte importante de informação sobre a qualidade do curso;

b) São feitas reuniões sistemáticas, ações isoladas, mas sem instrumento específico de avaliação, pois não existe uma política de avaliação formalmente constituída para cursos de especialização a distância;

c) É interessante saber as contribuições dos cursos do PNAP para a prática enquanto gestor, ideias e projetos implementados nas organizações, assim como para contribuir no planejamento de oferta de novas turmas.

Diante da confirmação de que não foi realizada avaliação sistemática com egressos da EAD e que é interessante para a instituição conhecer como os usuários avaliam o PNAP no âmbito do Vale do São Francisco, contemplou-se nesta pesquisa a identificação de "preocupações e questões" tratadas na avaliação do curso (WORTHEN; SANDERS; FITZPATRICK, 2004, p. 98) por grupo de interesse constituído por egressos do curso de 
Especialização em Gestão em Saúde, ou seja, profissionais da área de gestão de organização de saúde pública.

Destaca-se a relevância do estudo, diante da possibilidade de refletir sobre a pluralidade de ideias aplicáveis à avaliação de programas educacionais, além de possibilitar a identificação das necessidades de múltiplos atores envolvidos no processo avaliativo e interessados no programa, contribuindo para a melhoria das práticas avaliativas nas instituições de ensino.

\section{AVALIAÇÃO: DA MENSURAÇÃO À NEGOCIAÇÃO}

As definições de avaliação são interpretações mentais que refletem o contexto histórico e as suposições filosóficas das pessoas quanto à condução do propósito da avaliação, consequência de um processo de evolução, construção e reconstrução, e que, com o passar do tempo, tornou-se mais fundamentada e esclarecida (GUBA; LINCOLN, 1989).

Em relação aos significados da avaliação, Monteiro de Freitas (2010) elenca três abordagens: centrada em objetivos, descritiva e valorativa. A primeira geralmente utilizada para comparar objetivos do programa com os resultados alcançados (TYLER, 1977), a segunda utilizada para estudos diagnósticos, informações úteis à tomada de decisão (STUFFEBEAM, 1978) e, por último, a compreensão da avaliação como juízo de valor (valor ou mérito) para auxiliar a tomada de decisões (SCRIVEN, 1967; STAKE, 1975; GUBA; LINCOLN, 1989).

Essas gerações, de acordo com Guba e Lincoln (1989), são classificadas de acordo com as influências envolvidas: mensuração (primeira geração); descrição (segunda geração), avaliação baseada em juízo de valor (terceira geração), propondo, ainda, a avaliação como negociação (Quarta Geração), com enfoque responsivo e adoção da metodologia construtivista.

Worthen, Sanders e FitzPatrick (2004) classificam a avaliação de acordo com o tipo de abordagem: centrada em objetivos, na administração, no consumidor (expectativas), na experiência (especialistas), no adversário e centrada nos participantes. Em um contínuo da avaliação utilitarista versus construtivista, as duas primeiras estão próximas da avaliação utilitarista; as duas últimas aproximam-se da avaliação intuicionista-pluralista.

A avaliação centrada nos participantes é consequência da reação de teóricos, a partir de 1967, em relação ao predomínio de avaliações que não consideram o ambiente do 


\section{PERCEPÇÃO DAS CONTRIBUIÇÕES DA FORMAÇÃO EM GESTÃO EM SAÚDE DO PNAP A PARTIR \\ DA VISÃO DE EGRESSOS: UMA AVALIAÇÃO NEGOCIADA E CONTEXTUALIZADA \\ DOI: http://dx.doi.org/10.5007/1983-4535.2017v10n4p269}

programa e as experiências com as atividades desenvolvidas, bem como diante da incapacidade de reconhecimento do pluralismo de valores em torno de qualquer programa e a limitações metodológicas em processos avaliativos. Essa incapacidade é considerada por Guba e Lincoln (1989) como uma das fraquezas das gerações anteriores.

A avaliação centrada no juízo de valor sobre o mérito e sobre a importância do objeto avaliado (valor contextual) avançou em relação às anteriores, porém ainda com tendência ao gerencialismo, geralmente com avaliações encomendadas por clientes ou patrocinadores (GUBA; LINCOLN, 1989), mas sem julgamento das suas ações e práticas administrativas, desempoderando outros interessados. Daí a necessidade de o avaliador desempenhar, também, a função educativa ao envolver os interessados pelo programa avaliado.

\subsection{AVALIAÇÃO CENTRADA NOS PARTICIPANTES}

A avaliação centrada em participantes de programas educacionais foi desenvolvida, a partir de 1970, com o objetivo de identificar as preocupações e problemas que respondessem a necessidades de determinados grupos e teve como proponentes os autores Stake, Patton, Guba e Lincoln, Rippey, MacDonald, Parlett e Hamilton e Cousin e Earl (WORTHEN; SANDERS; FITZPATRICK, 2004). A abordagem tem como vantagens o foco na descrição e no julgamento, o interesse pelo contexto do programa e ou curso avaliado e a ênfase na compreensão. O desenvolvimento de um plano de avaliação, o uso de raciocínio indutivo e a adoção de pluralidade de ideias no processo avaliativo constituem outras vantagens da avaliação centrada nos participantes. Vale registrar que existe complexidade em termos de execução não diretiva e de custos elevados.

De acordo com Worthen, Sanders e Fitzpatrick (2004), o custo nesse tipo de abordagem tem sido considerado uma limitação grave em tempos de crise, por exigir trabalho intensivo, bem como por requerer a presença do avaliador nas observações, anotações e relatórios. Acrescenta-se a isso a disponibilização de tempo por parte de todos os interessados.

No que tange à avaliação de cursos ofertados pelo sistema UAB, há que se considerar, inclusive, a complexidade em termos de diversidade de público que compartilha o ambiente virtual de aprendizagem para a construção das ações educacionais permitidas pelos avanços de Tecnologias da Informação e da Comunicação (TICs) (BELLONI, 2009), bem como a compatibilização dessas TICs para auxiliar os processos de mediação pedagógica (RISTOFF, 


\section{PERCEPÇÃO DAS CONTRIBUIÇÕES DA FORMAÇÃO EM GESTÃO EM SAÚDE DO PNAP A PARTIR DA VISÃO DE EGRESSOS: UMA AVALIAÇÃO NEGOCIADA E CONTEXTUALIZADA \\ DOI: http://dx.doi.org/10.5007/1983-4535.2017v10n4p269}

2007; KUO et al., 2014; KISHI; PASSOS, 2015; BELLONI, 2010; MIL; PIMENTEL, 2010; ALMEIDA, 2007; VERHINE, 2015).

Quadro 1 Principais contribuições dos criadores da avaliação centradas nos participantes

\begin{tabular}{|l|l|}
\hline \multicolumn{1}{|c|}{ Autor } & \multicolumn{1}{c|}{ Contribuições } \\
\hline $\begin{array}{l}\text { Stake (1967; } \\
1975 ; 1978 ;\end{array}$ & $\begin{array}{l}\text { Primeiro teórico a dar impulso no campo da educação; criador do quadro } \\
\text { conceitual de referências das faces da avaliação, atos: descrição e julgamento. }\end{array}$ \\
$\begin{array}{l}\text { 1980; 1988; } \\
\text { Ofereceu concepções e princípios para o avanço da abordagem como avaliação } \\
\text { responsiva pluralista, tendo como foco a discussão das preocupações e dos } \\
\text { problemas de determinado grupo/programa. }\end{array}$ \\
\hline Guba (1969) & Impulsionou a busca por alternativas da abordagem racionalista na educação. \\
\hline $\begin{array}{l}\text { Parlett e } \\
\text { Hamilton (1976) }\end{array}$ & $\begin{array}{l}\text { Propuseram a avaliação iluminadora, preocupada com descrição e interpretação } \\
\text { em detrimento da mensuração e da previsão. }\end{array}$ \\
\hline Rippey (1973) & $\begin{array}{l}\text { Criticou a insensibilidade das abordagens no que tange ao impacto sobre os } \\
\text { responsáveis pelo programa avaliado, propondo a avaliação transacional. }\end{array}$ \\
\hline $\begin{array}{l}\text { MacDonald } \\
\text { (1974; 1976) }\end{array}$ & $\begin{array}{l}\text { Demonstraram preocupação com mau uso das informações com finalidades } \\
\text { políticas questionáveis em detrimento dos direitos da comunidade envolvida. }\end{array}$ \\
\hline $\begin{array}{l}\text { Guba; Lincoln } \\
(1981 ; 1989)\end{array}$ & $\begin{array}{l}\text { Após o exame das abordagens existentes, aceitaram, apenas, a avaliação } \\
\text { responsiva de Stake, que foi incorporada à avaliação naturalista para a criação de } \\
\text { abordagem com adoção do paradigma construtivista. }\end{array}$ \\
\hline $\begin{array}{l}\text { Patton (1975; } \\
1986 ; 1990 ;\end{array}$ & $\begin{array}{l}\text { Contribuiu muito com a abordagem a partir de sua experiência com avaliação de } \\
\text { campo. }\end{array}$ \\
\hline 1994$)$
\end{tabular}

Fonte: Elaboração própria com base em Worthen, Sanders e Fitzpatrick (2004).

As avaliações com uso da abordagem centrada nos participantes apresentam as seguintes características: a) a compreensão deriva do ambiente do programa; b) uso de múltiplos dados por meio de representações subjetivas e objetivas, qualitativas e quantitativas; c) a avaliação evolui de acordo com a experiência dos envolvidos, não seguindo um plano padronizado; e d) todas as perspectivas são aceitas como corretas em respeito à representação de realidades múltiplas, cabendo ao avaliador retratar essas realidades, sendo importante "responder às realidades do programa e às reações, preocupações e problemas dos participantes" em vez de seguir um plano prescrito com questões predeterminadas e problemas definidos (WORTHEN; SANDERS; FITZPATRICK, 2004, p. 230).

\subsection{AVALIAÇÃO COMO NEGOCIAÇÃO}

Após examinar as abordagens da avaliação de programas, Guba e Lincoln (1981) concordaram com a avaliação responsiva proposta por Stake (1975), noção incorporada à investigação naturalista, criando uma abordagem que adotou o paradigma construtivista e se concentrou na avaliação como empoderamento dos interessados. A avaliação como 


\section{PERCEPÇÃO DAS CONTRIBUIÇÕES DA FORMAÇÃO EM GESTÃO EM SAÚDE DO PNAP A PARTIR \\ DA VISÃO DE EGRESSOS: UMA AVALIAÇÃO NEGOCIADA E CONTEXTUALIZADA \\ DOI: http://dx.doi.org/10.5007/1983-4535.2017v10n4p269}

negociação (GUBA; LINCOLN, 1989) engloba aspectos positivos das três gerações anteriores, mas tem como característica a negociação, permitindo a integração de juízos, critérios e ações envolvidas no processo avaliativo, caracterizando, portanto, como uma abordagem alternativa que tem como enfoques organizacionais as reivindicações, preocupações, e questões (RPQ) dos sujeitos colocados em evidência pela avaliação (stakeholder). Nesse contexto, a abordagem também é chamada de avaliação construtivista responsiva.

Para Guba e Lincoln (1989), o termo responsivo ou respondente significa um novo caminho, uma forma diferente de avaliar, tendo como parâmetros e limites a interação e a negociação no processo avaliativo. Já o termo construtivista representa a metodologia a ser utilizada na condução da avaliação, daí poder ser chamada também de avaliação interpretativa ou hermenêutica, propondo a existência de resultados condicionados à interação entre observador e observado.

A determinação de questões de pesquisa, bem como das informações que devem ser coletadas dependem do modelo de avaliação adotado pelo pesquisador. Assim, elementos como identificação de variáveis (primeira geração), discrepância entre objetivos e desempenho (segunda geração), informações inerentes à tomada de decisões, efeitos, juízos de valor (terceira geração) constituem "elementos de focalização", também chamados de “organizadores avançados” (GUBA; LINCOLN, 1989, p. 48). No caso da avaliação responsiva, as reivindicações, preocupações e questões, identificadas pelos interessados, funcionam como organizadores avançados ou enfoques organizacionais da abordagem em relação ao curso avaliado. Esses organizadores são implementados de acordo com os preceitos da metodologia construtivista.

A reivindicação pode ser qualquer alegação apresentada por um interessado; a preocupação, qualquer afirmação desfavorável ao objeto avaliado; e a "questão" diz respeito a qualquer aspecto sobre o qual possa haver discordância. Essas RPQ devem ser identificadas pelo avaliador e abordadas na avaliação. Consoante aos grupos de interesse, Guba e Lincoln (1981) identificam: a) os representantes - envolvidos na produção e implementação do programa avaliado; b) os beneficiários - pessoas que tiram proveito do uso do programa avaliado; e c) as vítimas - pessoas afetadas negativamente pelo uso do programa avaliado.

Para Stake (1975, p. 3) citado por Worthen, Sanders e Fitzpatrick (2004, p. 231), a "abordagem responsiva tenta responder às formas naturais pelas quais as pessoas assimilam 
informações e chegam à compreensão". Sendo assim, entre tantas coisas que o avaliador deve fazer, ele deve descobrir o que tem valor para seu público, e a avaliação deve responder às exigências dos interessados, devendo ser voltada mais para as atividades do programa do que para seus objetivos. Para a organização da avaliação responsiva, devem ser observadas as fases de: a) identificação dos grupos de interesse; b) identificar as reivindicações, preocupações e questões; c) coletar informações para resolver RPQ não resolvidas; e d) negociar com a finalidade obter consenso sobre aspectos de discordância.

O referencial teórico-metodológico da avaliação negociada foi utilizado por vários pesquisadores tanto na área de serviços de saúde quanto em outras áreas. Kantorski et al. (2009) ao realizar pesquisa na área de saúde mental, afirmou que a Avaliação da Quarta Geração permite aos sujeitos de pesquisa: a partilha de decisões, o exercício do controle sobre a avaliação, o conhecimento das etapas metodológicas, garantindo a a participação de forma hermenêutica e dialética na busca de trabalhar conflitos e gerar consensos. Abordagem foi utilizada também por Meirelles; Hypolito; Kantorski (2012), Cossetin (2010), Mielke e Olchowski (2010); Schneider e outros (2008) e Furtado (2001). Brandão (2007) utilizou a avaliação participativa como oportunidade de aprendizagem em avaliação de programas e projetos sociais. Já Paixão (2012) propôs indicadores de avaliação de impacto em cursos de mestrado profissional a partir da avaliação como negociação.

\section{CARACTERIZAÇÃO DA PESQUISA}

A pesquisa é predominantemente qualitativa, abordagem que tem a avaliação de programas como um de seus "principais terrenos" (DENZIN; LINCOLN, 2006, p.37), podendo ser classificada quantos aos objetivos como exploratória, pois visa identificar, a partir da percepção de egressos, as contribuições do processo formativo recebido. O conceito utilizado para o estudo avaliativo foi o de avaliação de programas, dimensão avaliação de egressos, dentro do contexto da avaliação institucional e de cursos, utilizando o princípio da negociação (GUBA; LINCOLN, 1989) como característica no processo avaliativo.

Os sujeitos de pesquisa são ex-alunos, concluintes da primeira turma do curso de especialização em Gestão em Saúde do PNAP no âmbito da UNIVASF, corte temporal 2015.1, período do encerramento da turma, com um universo de 70 egressos. Os aspectos éticos foram avaliados pelo Comitê de Ética em Pesquisa da UNIVASF por meio do Parecer consubstanciado de número 1.243.711. 


\subsection{GRUPO FOCAL COMO TÉCNICA DE COLETA DE INFORMAÇÃO}

Para a coleta de informações, foram realizados grupos focais formados por egressos com o objetivo de possibilitar a construção de forma negociada e contextualizada dos aspectos a serem avaliados qualitativamente no curso, técnica também utilizada para a avaliação das contribuições da formação com base no que foi construído coletivamente (aspectos identificados).

A técnica do grupo focal é derivada das entrevistas grupais (MORGAN, 1997), utilizada para o debate de temas comuns ao grupo (GASKELL, 2008), tem o processo coletivo como base e são úteis nos estudos de natureza formativa (GUBA; LINCOLN, 1989). A técnica está entre a observação participante e as entrevistas em profundidade (GONDIM, 2003), podendo ser utilizada em organizações formais para auxiliar na "introdução de programas, na tomada de decisões, na aprendizagem organizacional, no diagnóstico e avaliação da qualidade de serviços, assim como na geração de novas ideias" (GONDIM, 2003, p.160), além de ser interessante quando se tem pouco conhecimento sobre o fenômeno pesquisado (PAIXÃO, 2012).

A técnica foi adotada neste estudo por permitir a interação entre os participantes e por possibilitar conhecimentos aprofundados sobre o tema, de acordo com as prioridades estabelecidas pelos participantes, adequada, portanto, ao objetivo da pesquisa. A coleta foi realizada durante os meses de outubro e dezembro de 2015 em momentos presenciais e online.

Quadro 2 Matriz de planejamento da abordagem utilizada

\begin{tabular}{|c|c|c|c|c|}
\hline Conceito & Dimensão & Característica & $\begin{array}{c}\text { Fontes de } \\
\text { coleta }\end{array}$ & $\begin{array}{c}\text { Tratamento de } \\
\text { informações }\end{array}$ \\
\hline $\begin{array}{c}\text { Contribuições dos cursos de } \\
\text { Especialização do PNAP na Qualificação } \\
\text { de Gestores Públicos }\end{array}$ & Egressos & Negociação & $\begin{array}{c}\text { Grupos } \\
\text { Focais }\end{array}$ & $\begin{array}{c}\text { Discurso do } \\
\text { Sujeito } \\
\text { Coletivo }\end{array}$ \\
\hline
\end{tabular}

Fonte: elaboração própria (2016)

\section{PROCEDIMENTOS ADOTADOS PARA CONSTRUÇÃO DA AVALIAÇÃO}

Após submeter a proposta de pesquisa à Plataforma Brasil, base nacional e unificada de registros de pesquisas envolvendo seres humanos para todo o sistema CEP/Conep, obtevese acesso ao banco de dados na Secretaria de Educação a Distância da UNIVASF, mediante 
autorização dos gestores responsáveis, a fim de conseguir dados dos egressos da especialização em Gestão em Saúde do PNAP.

Ao planejar a pesquisa, a pretensão era formar três grupos focais condicionados à disponibilidade dos participantes, observando, para tanto, o limite máximo de 12 participantes (MORGAN, 1997; 1998) para não inviabilizar a participação de todos os integrantes do grupo (GONDIM, 2003). Nesse sentido, os participantes do grupo focal foram convidados para a discussão, via endereço eletrônico, extraído do banco de dados fornecido pela Secretaria do curso de especialização em Gestão em Saúde do PNAP, convite reiterado por telefone, com sessões em dias e horários alternativos.

De acordo com as respostas ao convite enviado a todos os egressos, o primeiro grupo foi agendado para o polo de apoio presencial na cidade de Juazeiro, estado da Bahia, com sete intenções de participação, porém foi cancelado devido à confirmação de apenas duas pessoas no dia do evento. O segundo, confirmado para a cidade de Petrolina-PE, campus sede da instituição, contava inicialmente com nove confirmações. Os sujeitos de pesquisa reuniram-se na sala de tutoria da Secretaria de Educação a Distância, no dia 02 de outubro de 2015, com presença de sete pessoas. Além do mediador (pesquisadora), participaram da sessão um observador e um controlador de tempo.

Seguindo o planejamento inicial da pesquisa, realizou-se nova sessão no dia dois de dezembro de 2015, utilizando-se de ferramenta online, sendo permitida a participação presencial, formando um grupo misto. $\mathrm{O}$ agendamento de grupo online com uso da ferramenta Skype teve o propósito de contemplar um maior número de participantes em relação ao primeiro grupo, logo, o convite foi enviado aos egressos de todos os polos. Em que pese o esforço envidado no sentido de ampliar a inclusão e a participação de interessados, apenas sete manifestaram interesse em participar da discussão, a qual contou, também, com a participação presencial, ficando um grupo de modalidade mista (presencial e online).

Algumas dificuldades em termos de conexão impediram a participação efetiva de todos os participantes. Vale ressaltar que o tamanho entre quatro a 10 pessoas foi convencionado para realização da técnica (GONDIM, 2003), porém o número de participantes depende do grau de interesse despertado em relação assunto.

Os egressos formalizaram o termo de consentimento livre e esclarecido (TCLE) para a participação na pesquisa, incluindo gravação e uso científico das informações, termo assinado durante a realização dos grupos presenciais. Os egressos que participaram exclusivamente do 
grupo online formalizaram o termo em formulário pela internet. Em todas as etapas, os grupos foram conduzidos pela pesquisadora que atuou como moderadora.

Seguindo o princípio da negociação, houve pouca intervenção por parte da moderadora, a qual apresentou o roteiro com o objetivo de discutir sobre avaliação do curso de especialização em Gestão em Saúde, repassando as orientações básicas sobre direito de participação, duração da sessão, foco da discussão (GONDIM, 2003). Em seguida, fez uma breve contextualização sobre regulamentação de cursos de pós-graduação lato sensu, lançando as seguintes questões para os dois momentos da discussão.

a) Primeiro momento: identificação dos indicadores a serem avaliados.

I - Se você fosse avaliar o seu curso, quais aspectos da qualificação em Gestão em Saúde você levaria em consideração? O que você iria avaliar?

II - Gostaria de acrescentar algum ponto nos itens a serem avaliados? Por quê?

III - Dos pontos levantados, quais você considera mais relevantes?

b) Segundo momento: Avaliação dos aspectos identificados no primeiro momento do grupo.

I - Quais as contribuições desse aspecto para a melhoria das práticas de gestão em saúde?

Segundo Trad (2009), para a elaboração do roteiro, deve-se levar em consideração a existência de poucas questões de forma a permitir flexibilidade na condução do grupo. Dessa forma, foram incorporadas questões que emergiram durante a discussão, relacionadas ao objeto de estudo.

Todas as reuniões foram gravadas e as informações foram transcritas, mantendo a fala integral dos participantes, material de análise desta pesquisa (BAUER; GASKELL, 2008). A interpretação das informações deu-se por meio do Discurso do Sujeito Coletivo (DSC).

\subsection{DSC COMO ESTRATÉGIA DE ANÁLISE DAS INFORMAÇÕES}

A pesquisa qualitativa não possui um conjunto de métodos ou práticas exclusivamente próprios, segundo Denzin e Lincoln (2006), possibilitando aos pesquisadores qualitativos a utilização de análise da narrativa, de conteúdo, do discurso além de outras específicas para a abordagem quantitativa. Sendo assim, adotou-se neste estudo avaliativo a técnica do Discurso do Sujeito Coletivo (DSC) como estratégia de análise das informações obtidas por meio dos grupos focais. Trata-se de um método fundamentado nos pressupostos da teoria das 
representações sociais (LEFÈVRE; LEFÈVRE, 2003; FLICK, 2009), e tem como proposta a organização e tabulação de dados qualitativos de natureza verbal obtidos de depoimentos, ou seja, é uma modalidade de apresentação de resultados de pesquisas qualitativas que visa expressar o pensamento de um grupo, como se este grupo fosse o emissor de um discurso (LEFÈVRE; LEFÈVRE, 2003; 2009; FIGUEIREDO; CHIARI; GOULART, 2013).

Com base nos estudos de Lefèvre e Lefèvre (2003), os trechos mais significativos dos depoimentos individuais, destacados pelo pesquisador, são as expressões-chave (ECH), as quais revelam a essência do conteúdo. A descrição sintética do sentido do conjunto homogêneo de cada ECH é expressada pela ideia central (IC). Logo, a junção das ECH com a mesma IC forma o Discurso-síntese (DSC), expressando o pensamento do grupo como se fosse um discurso individual. Nos depoimentos ainda pode ser encontrado outro operador, denominado ancoragem, a qual revela uma teoria ou ideologia expressada pelo autor do discurso, recurso metodológico não utilizado nesta pesquisa.

Alinhado a esse pensamento, a expressão da opinião dos participantes do grupo focal, nesta pesquisa, deu-se por meio da transcrição dos depoimentos verbais coletados durante as duas sessões realizadas, tendo como parâmetros as expressões-chave $(\mathrm{ECH})$ sobre os aspectos do curso de especialização em Gestão em Saúde, identificados como relevantes durante a avaliação negociada, e agrupadas em ideia central (IC), expressão representativa do conjunto das ECH nos discursos dos participantes para cada aspecto avaliado. Esse agrupamento possibilitou a construção do DSC, o qual foi redigido na primeira pessoa do singular, mantendo a discursividade sobre cada aspecto avaliado (LEFÈVRE; LEFÈVRE, 2003; FIGUEIREDO; CHIARI; GOULART, 2013).

\section{APRESENTAÇÃO E DISCUSSÃO DOS RESULTADOS}

Todos os participantes deste estudo são egressos do curso de Especialização em Gestão em Saúde da Universidade Federal do Vale do São Francisco, turma 2013/2014, técnicos da área de saúde, com formação nas áreas de Farmácia, Enfermagem, Psicologia e Fisioterapia. Dos participantes, quatro são gestores públicos.

Os resultados apresentados neste estudo referem-se às perguntas: a) se você fosse avaliar o seu curso, que aspectos seriam priorizados, ou seja, o que você iria avaliar; e b) quais as contribuições do aspecto avaliado para a melhoria das práticas em gestão em saúde? 


\section{PERCEPÇÃO DAS CONTRIBUIÇÕES DA FORMAÇÃO EM GESTÃO EM SAÚDE DO PNAP A PARTIR \\ DA VISÃO DE EGRESSOS: UMA AVALIAÇÃO NEGOCIADA E CONTEXTUALIZADA \\ DOI: http://dx.doi.org/10.5007/1983-4535.2017v10n4p269}

As reivindicações, preocupações e questões identificadas nos discursos dos participantes sobre os aspectos identificados por meio da avaliação negociada estão representadas no quadro 3, enquanto as representações sociais sobre as contribuições dos aspectos avaliados pelos participantes estão sintetizadas no quadro 4, no qual são apresentadas, para cada IC, as frequências das ECH utilizadas na construção do discursosíntese.

Para os aspectos identificados e priorizados na avaliação negociada, foram contabilizadas 171 ECH classificadas e distribuídas em 16 IC (IC - A até IC - P), frequência demonstrada no quadro 3.

Quadro 3 Síntese das representações sociais sobre aspectos avaliativos priorizados

\begin{tabular}{|c|l|c|}
\hline \multicolumn{2}{|c|}{ Ideias Centrais (IC) } & Frequência ECH \\
\hline IC - A & A realização de atividades em grupo foi positiva & 20 \\
\hline IC - B & O conteúdo interativo ajuda a despertar o interesse no educando & 20 \\
\hline & $\begin{array}{l}\text { Fóruns de discussão como ferramenta de aprendizagem e de desenvolvimento de } \\
\text { habilidades interpessoais }\end{array}$ & 18 \\
\hline IC - - D & O apoio do tutor foi importante para minha permanência no curso & 14 \\
\hline IC - E & Tenho ressalvas sobre a minha orientação & 14 \\
\hline IC - F & Os docentes eram preparados, mas em alguns faltou o olhar como gestor & 12 \\
\hline IC - G & Atividades e métodos de avaliação & 10 \\
\hline IC - H & As atividades interativas melhoram a qualidade do curso & 10 \\
\hline IC - I & As disciplinas trabalhadas foram proveitosas. Não tenho críticas, exceto o TCC & 10 \\
\hline IC - J & Algumas disciplinas poderiam ser mais contextualizadas & 10 \\
\hline IC - K & O meu processo de orientação foi tranquilo. A minha experiência não foi ruim & 7 \\
\hline IC - L & Limitações enfrentadas pelos gestores em saúde versus implantação de melhorias & 7 \\
\hline IC - M & O Material didático foi bom, atualizado e pertinente ao curso & 6 \\
\hline IC - N & Sugestões de melhorias para novas turmas & 5 \\
\hline IC - O & Dificuldades para realização de atividades práticas durante o curso & 4 \\
\hline IC - P & O fórum de discussão é uma ferramenta enriquecedora & 4 \\
\hline
\end{tabular}

Fonte: Elaboração própria (2016).

Já as contribuições da formação para a melhoria das práticas de gestão em saúde, foram identificadas em $68 \mathrm{ECH}$ correspondentes a quatro IC (IC-Q até IC-T), frequências demonstradas no quadro 4.

Vale ressaltar que, com este estudo, não se pretende resolver todas as reivindicações, preocupações e questões representadas pelas IC identificadas. Sendo assim, por uma questão de limitação de tempo inerente à pesquisa, bem como devido à questão de espaço físico, foram apresentados, neste artigo, os discursos do sujeito coletivo das IC-A e IC-B, porém discutidos as 10 primeiras IC, as quais em conjunto representam $81 \%$ das IC do quadro 3 . A IC-N foi inserida na discussão por representar reflexões sobre melhorias para novas turmas. 


\section{PERCEPÇÃO DAS CONTRIBUIÇÕES DA FORMAÇÃO EM GESTÃO EM SAÚDE DO PNAP A PARTIR \\ DA VISÃO DE EGRESSOS: UMA AVALIAÇÃO NEGOCIADA E CONTEXTUALIZADA \\ DOI: http://dx.doi.org/10.5007/1983-4535.2017v10n4p269}

No que se referem às contribuições da formação, foi apresentado o DSC da IC-R, porém contempladas na discussão todas as IC do quadro 4.

Quadro 4 Síntese das representações sociais sobre as contribuições da formação

\begin{tabular}{|c|c|c|c|}
\hline Aspecto & \multicolumn{2}{|r|}{ Ideias Centrais (IC) } & $\begin{array}{c}\text { Frequência } \\
\text { ECH }\end{array}$ \\
\hline \multirow{4}{*}{ 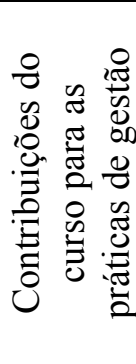 } & $\mathrm{IC}-\mathrm{Q}$ & $\begin{array}{l}\text { O curso possibilitou o desenvolvimento de habilidades } \\
\text { gerenciais, me deixando mais capacitado e mais confiante }\end{array}$ & 21 \\
\hline & $\mathrm{IC}-\mathrm{R}$ & $\begin{array}{l}\text { Ampliei a minha percepção sobre o SUS e aplico os } \\
\text { conhecimentos na prática }\end{array}$ & 20 \\
\hline & $\mathrm{IC}-\mathrm{S}$ & $\begin{array}{l}\text { Os conteúdos trabalhados permitem ampliar o limite de ação do } \\
\text { gestor }\end{array}$ & 17 \\
\hline & $\mathrm{IC}-\mathrm{T}$ & $\begin{array}{l}\text { O PNAP contribui para a melhoria da execução de políticas } \\
\text { públicas de saúde }\end{array}$ & 10 \\
\hline
\end{tabular}

Fonte: Elaboração própria (2016).

O quadro 5 apresenta o discurso síntese da IC-A, ou seja, a junção das ECH relacionadas à realização de atividades em grupo em curso a distância, aspecto priorizado pelos participantes do grupo focal para avaliação.

Quadro 5 Discurso do Sujeito coletivo da IC-A

A realização do trabalho em grupo foi positiva

Eu saúdo muito o professor que tentou fazer com a gente uma atividade em grupo. Ali ele demonstrou empenho e principalmente persistência porque foi a coisa mais difícil do mundo juntar pessoas que não se conheciam num grupo. Foi positivo, foi bom. Foi assim, louvável o que ele fez! A minha presença foi virtual. Consegui montar o grupo, a gente conseguiu montar e conversar. Pra mim, contribuiu. A gente discutiu, conversou e até dividiu um pouco de angústia. Contribuiu no sentido de, por exemplo, perceber como é difícil você lidar dentro de um grupo com as singularidades de cada um e gerir aquilo. Em termos de nota, nós não saímos tão bem quanto idealizamos, mas aquilo mostra, por exemplo, a importância de um grupo pensar numa mesma linha de raciocínio e naquele momento. Foi muito positivo, foi muito integrador. Ah, deixou, deixou até saudade! é... houve, mas foi pouco, né? Mas sei que é muito difícil, acho que a proposta da pós é exatamente dar o conhecimento no momento louco que a gente vive, né? De dificuldade de se encontrar de fazer grupos. Exatamente! A questão de o grupo ter sido virtual, em nenhum momento isso foi uma barreira pra realização do trabalho, barreiras foram outras, esforços presencias. Barreiras seriam físicas ou não físicas, elas existiriam, mas a realização do grupo foi muito positiva. A gente conseguiu realmente realizar o trabalho.

A partir do DSC da IC-A, conclui-se que há um desejo, por parte do grupo, de integração da turma durante a realização do curso, convergindo para o investimento, por parte da gestão dos cursos, em atividades de interação entre os alunos de cursos ofertados a distância. Percebe-se, a partir do DSC, que a iniciativa dos docentes foi positivamente avaliada, convergindo para a aceitação, por parte dos interessados, do tipo de atividade realizada. O discurso do grupo remete aos ensinamentos de Moran (2000) no sentido de que 


\section{PERCEPÇÃO DAS CONTRIBUIÇÕES DA FORMAÇÃO EM GESTÃO EM SAÚDE DO PNAP A PARTIR \\ DA VISÃO DE EGRESSOS: UMA AVALIAÇÃO NEGOCIADA E CONTEXTUALIZADA \\ DOI: http://dx.doi.org/10.5007/1983-4535.2017v10n4p269}

se aprende com a interação com o outro com o mundo e quando se faz questionamentos, estabelecendo vínculos. Nesse sentido, resultados de estudos anteriores apontam a necessidade de investir em variedade dos meios de comunicação e de disponibilização de recursos de interação entre aluno-professor, aluno-conteúdo e aluno-aluno (ARBAUGH; HORNIK, 2006; KUO, et al. 2014).

Outro ponto tido como relevante pelos participantes diz respeito à inclusão de recursos tecnológicos capazes de tornar as atividades mais dinâmicas, a exemplo de videoaulas e webconferência. A ideia de dessa dinamicidade encontra-se no DSC do quadro 6.

Quadro 6 Discurso do Sujeito Coletivo da IC - B

O conteúdo interativo ajuda a despertar o interesse no educando

Outro aspecto de avaliação seria os materiais do ensino a distância, né? Os materiais utilizados, pdf, vídeo. Videoaula em ensino a distância é de suma importância. A videoconferência. Acho que há uma má interpretação do ensino a distância. Acham que o ensino a distância é só mandar o material para o aluno, o PDF. O aluno tem que ser autodidata e nunca aparece uma videoconferência ou um vídeo do professor lá, conversando, explicando o conteúdo. É de suma importância no ensino a distância o material. Alguns professores postaram vídeo. Nós tivemos em algumas disciplinas. E era bem interessante - o aluno ficava mais interessado no conteúdo porque o professor estava ali passando um conhecimento pra ele. É diferente do professor que escreve uma frase lá, faz um comentário pra o aluno ler o pdf e depois fazer uma síntese. Acho que investir nisso, não apenas no conteúdo pelo conteúdo, mas investir no desenvolvimento dessas outras capacidades que são tão importantes quanto. Eu ficaria com o material! Eu senti falta das conferências, dos vídeos, vídeo aulas. As videoaulas ... a gente sentiu muita falta disso, era mais bombardeado de textos. E assim, quando tem um vídeo, quando tem algo mais didático a gente não se sente nesse processo tão sozinho, que é um desafio da educação a distância, faltou em quantidade, mas jamais em qualidade na minha percepção. Até a própria apresentação do professor, você já fica familiarizado com ele no vídeo. Aquela disciplina que teve os videozinhos, eu colocaria como a melhor! eu acho que tem que ter um envolvimento também, porque mesmo sendo a distância a gente sente quando... "eita tá diferente". A gente já achava mais legal aquela disciplina.

De acordo com o discurso dos participantes, a interação deve fazer parte das atividades propostas. Essa avaliação contextualizada permite refletir sobre o poder de influência que as ferramentas exercem sobre o processo educativo.

No tocante a discussões mediadas por fóruns, como recursos de aprendizagem, destaca-se a necessidade de oferecer, ao aluno, habilidades orientadas para o desenvolvimento de seu autoconhecimento e de sua autonomia, possibilitando a participação colaborativa e as reflexões críticas na aprendizagem. Quando não há essa participação recíproca, o discente percebe-se em um processo solitário de aprendizagem, logo não há retorno imediato possibilitado pela interação (BELLONI, 2009). Infere-se que a mediação por parte de tutores e professores nas discussões em fóruns está relacionada ao estabelecimento de vínculos entre 


\section{PERCEPÇÃO DAS CONTRIBUIÇÕES DA FORMAÇÃO EM GESTÃO EM SAÚDE DO PNAP A PARTIR \\ DA VISÃO DE EGRESSOS: UMA AVALIAÇÃO NEGOCIADA E CONTEXTUALIZADA \\ DOI: http://dx.doi.org/10.5007/1983-4535.2017v10n4p269}

os atores e o conteúdo, bem como à atribuição de significados para a atividade mediada (MORAN, 2000; MARTINS; GARBIN, 2011), podendo desenvolver habilidades interpessoais.

Em relação aos recursos didáticos, o discurso-síntese enfatiza a importância da divulgação de conteúdos interativos e por diversos meios para despertar o interesse do educando, convergindo para os resultados de pesquisas sobre aprendizagem em cursos a distância (KUO; WALKER; SCHRODER, BELLAND, 2014; ANDERSON, 2003; ARBAUGH, 2005; 2006).

O papel da tutoria foi outro aspecto priorizado para avaliação, considerado pelos participantes como necessário à permanência dos discentes no curso. De acordo com o discurso do grupo, o tutor atua como mediador tanto em relação às atividades do curso quanto na utilização da plataforma, o que é considerado como fator importante para mitigar a evasão, além de atuar como ponte entre discente, professor e coordenação.

Durante à negociação, os participantes priorizaram o processo de orientação do trabalho de conclusão de curso como aspecto importante na avaliação de curso a distância, conforme discurso síntese da IC - E. O DSC sobre a orientação do TCC reflete o desejo dos participantes de praticar os conhecimentos adquiridos no curso, de desenvolver um projeto de melhoria das práticas de gestão, condicionando esse exercício à entrega e dedicação por parte dos orientadores. Apontam essa parte do curso como uma fragilidade, suportando a reflexão quanto à gestão da EAD nesse ponto específico, uma vez que este vem surgindo como ponto de melhoria nas pesquisas sobre o PNAP, a exemplo dos estudos de Demarco $(2013 ; 2014)$.

Outro ponto destacado pelo grupo ressalta a qualificação dos docentes para os conteúdos trabalhados, sugerindo a possibilidade de aliar os conhecimentos acadêmicos à prática gerencial, no exercício da prática docente. A partir do DSC da IC-F é possível entender que houve certo consenso quanto a questões relacionadas à formação docente, uma vez que a experiência em gestão esperada pelos participantes, enquanto discentes do curso, estava direcionada aos orientadores de TCC, não sendo justo, para os participantes, avaliar a atuação docente durante todo o curso apenas em função de uma disciplina específica. Essa decisão reflete o enfoque responsivo da avaliação negociada e à metodologia dialética da avaliação centrada nos participantes (WORTHEN; SANDERS; FITZPATRICK, 2004; GUBA; LINCOLN, 1989) como forma de aumentar a responsabilidade com a utilização dos resultados (KANTORSKI, et al., 2009). 


\section{PERCEPÇÃO DAS CONTRIBUIÇÕES DA FORMAÇÃO EM GESTÃO EM SAÚDE DO PNAP A PARTIR \\ DA VISÃO DE EGRESSOS: UMA AVALIAÇÃO NEGOCIADA E CONTEXTUALIZADA \\ DOI: http://dx.doi.org/10.5007/1983-4535.2017v10n4p269}

Reforçando os argumentos da IC-A, os participantes atribuem importância à variedade de atividades propostas e a possibilidade de priorizar, nessas atividades, a orientação para o desenvolvimento de habilidades comportamentais (IC $-\mathrm{G})$. O discurso dos participantes enfatiza a relevância das metodologias participativas, permitindo concluir que o processo de avaliação foi tranquilo durante o curso, sugerindo disponibilizar feedback imediato para todas as atividades avaliativas, bem como a realização de atividades em grupo como forma de contribuir para ampliar habilidades interpessoais, argumento complementado pela IC-H, que apresenta um DSC sobre o uso de recursos utilizados para a construção de saberes, troca de opiniões e debates de ideias em cursos a distância, recursos esses oferecidos pela Plataforma Moodle, ambiente virtual de aprendizagem utilizado para a realização de atividades do curso. A utilização de um ou de outro recurso depende das habilidades comunicativas do professor e da metodologia adotada na sua prática docente.

Percebe-se que há uma preferência dos participantes pelas ferramentas que possibilitam a comunicação sincrônica, a exemplo de chat e webconferência, além da reflexão sobre os processos diacrônicos, a exemplo de fóruns de discussão. O ponto levantado nesse DSC é a interatividade como atributo para melhoria da qualidade do curso ofertado a distância, ou seja, é uma característica das atividades propostas e materiais didáticos que dever ser priorizado na avaliação de cursos a distância.

Dando continuidade à avaliação dos aspectos identificados durante o processo de negociação (GUBA; LINCOLN, 1989), os participantes aprovam a estrutura curricular, porém com várias ressalvas no que se refere ao processo de orientação do trabalho de conclusão de curso. A IC- I aponta para a adequação da estrutura curricular, porém indicando ser um indicador importante para avaliação, sugerindo, nesse sentido, a avaliação e/ou atualização pela própria gestão da EAD, convergindo para a importância da autoavaliação com vistas à manutenção da qualidade da formação e para o fortalecimento da instituição, (DIAS SOBRINHO, 2004; SINAES, 2004; ROTHEN, 2006; VERHINE; MONTEIRO DE FREITAS, 2012). Vale ressaltar que os conteúdos trabalhados nos cursos de especialização do PNAP foram positivamente avaliados em outras pesquisas sobre o programa (ISHIDA; STEFANO; ANDRADE, 2013; GROHMANN; RISS; BATTISTELLA, 2014), indicando a coerência do currículo com as atividades desempenhadas. Nesse sentido, os participantes discutiram a necessidade de contextualização dos conteúdos trabalhados para reforçar a importância dessas disciplinas para a formação em saúde. 
No que tange ao desenvolvimento de as atividades práticas e dinâmicas de grupo, a IC-N reúne as expressões-chave sobre sugestões de melhorias para as próximas turmas do curso. Destaca-se no DSC o desejo dos participantes em desenvolver atividades de aplicação prática no município, sugerindo a realização de parcerias para o desenvolvimento de projetos.

Passa-se agora para a apresentação das representações sociais sobre as contribuições da formação para a melhoria das práticas em gestão em saúde pública.

A IC-Q reúne as expressões-chave que representam a contribuição da formação para o desenvolvimento de habilidades gerenciais, para a capacitação de quadro de gestores, destacando, a partir dos discursos dos participantes, a importância atribuída ao curso de especialização em Gestão em Saúde, o julgamento de valor e mérito sobre aquilo que é importante para os grupos de interesse. Com outras abordagens, os três cursos de especialização do PNAP foram positivamente avaliados (ISHIDA; STEFANO; ANDRADE, 2013; GROHMANN; RISS; BATTISTELLA, 2014; DEMARCO, 2014).

No contexto das percepções de egressos, o curso contribuiu para a ampliação da visão dos gestores sobre o Sistema Único de Saúde (SUS), conforme DSC da IC-R.

Quadro 7 Discurso do Sujeito Coletivo da IC - R

\begin{tabular}{l} 
Ampliei a minha percepção sobre o SUS e aplico os conhecimentos na prática \\
\hline Meu olhar é outro, minha percepção é outra e é muito superior a que eu tinha anteriormente, pois saí \\
um profissional técnico da minha graduação, não saí pra questão do SUS. A pós me ajudou muito \\
nesse sentido. É importante a gente saber o que é o SUS, saber a história do SUS, e é importante \\
conhecer sobre todo esse aparato técnico - conhecer o papel do gestor, o que é que ele tem que fazer. \\
Essa formação ampla pra poder eu chegar a qualquer instância da saúde e ser um bom gestor. Isso! \\
Priorizou e ampliou, porque nós tivemos algumas atividades "árvore" de problemas que nós \\
construímos durante o curso pra resolver problemas de saúde dentro de um determinado local, do \\
município, como fazer esse levantamento, identificar o problema, trazer uma solução. Então a gente \\
começa a ampliar a percepção de que não estamos isolados nesse imenso sistema que é o SUS. De \\
fato, contribuiu com aspectos históricos relevantes. O conhecimento adquiriu um cunho prático com a \\
questão lá da unidade. Eu nunca fui gestor, mas hoje muito do que eu aprendi na pós-graduação eu \\
uso muito no hospital. Preciso de muitas coisas que aprendi na pós de gestão em saúde. Não \\
vivenciava antes na atenção básica, mas na parte assistencial tenho aproveitado muito do que aprendi. \\
O conhecimento da pós me ajudou muito na questão da Vigilância Epidemiológica do Estado. Tudo \\
foi uma soma de conhecimentos que eu pude aplicar no meu trabalho na coordenação. Houve uma \\
soma, uma ampliaçãa. Isso!
\end{tabular}

Os participantes relatam a ampliação de conceitos e aplicação dos conhecimentos em suas práticas profissionais. Para os participantes, os conteúdos trabalhados também permitiram ampliar o limite de ação do gestor em relação à implementação de programas e políticas. Infere-se, a partir dos $\mathrm{ECH}$, a inquietude dos participantes em transformar 
realidades, em aplicar conhecimentos, porém muitas vezes esbarrando nas limitações de gestão e de recursos financeiros, segundo eles. Acrescentam, ainda, que os conteúdos trabalhados contribuíram para ampliar o poder de decisão dos gestores em saúde. Por último, surgiram percepções sobre o PNAP, avaliado como instrumento capaz de trazer melhorias para a execução de políticas públicas de saúde (IC - T).

A partir da IC-S, conclui-se que os grupos de interesse avaliam qualitativamente satisfatória a pós-graduação lato sensu em Gestão de saúde e sua contribuição para a formação de quadros específicos para a execução de políticas públicas de saúde no Vale do São Francisco.

\section{CONSIDERAÇÕES FINAIS}

Para o desenvolvimento deste estudo com egressos, considerou-se avaliação como um ato político (GUBA; LINCOLN, 1989) que envolve grupos de interesses. Nesse sentido, verificou-se, inicialmente, a viabilidade da pesquisa, mediante a realização de sondagens por meio de entrevista exploratória com grupos de administradores do curso avaliado e com representante da Comissão Própria de Avaliação (CPA).

A partir de então, foram contempladas as preocupações e questões (WORTHEN; SANDERS; FITZPATRICK, 2004) do grupo de interesse constituído por egressos do curso de Especialização em Gestão em Saúde, com proposta inicial de pesquisa submetida à Plataforma Brasil, obtendo parecer favorável a sua aprovação, conforme parecer consubstanciado emitido pelo Comitê de Ética em Pesquisa da UNIVAS, protocolo 1.243.711.

Para identificar as contribuições do curso de especialização em Gestão em Saúde do PNAP/UNIVASF, a partir da percepção dos egressos, objetivo principal deste estudo, utilizou-se a técnica do Grupo Focal para coleta de informações, as quais foram construídas a partir da interação entre os participantes. Os discursos desses participantes foram interpretados por meio da análise do Discurso do Sujeito Coletivo (LEFÈVRE; LEFÈVRE, 2003).

Os discursos-síntese reúnem expressões sobre os indicadores da avaliação de cursos priorizados durante a negociação: papel da tutoria para permanência do aluno; materiais didáticos dialógicos para despertar o interesse do educando; processo de orientação durante o trabalho de conclusão de curso, sugerindo necessidade de entrega por parte dos orientadores; 
relevância das atividades práticas e visitas técnicas para a contextualização dos conteúdos trabalhados; contribuições da formação para ampliar conceitos sobre o SUS e aplicabilidade dos conhecimentos adquiridos; relevância do PNAP para a melhoria da execução de políticas públicas em saúde; contribuições da formação para as práticas de gestão dos profissionais formados; importância da mediação, por parte de professores e tutores, nos fóruns de discussão; realização de atividades em grupo em cursos EAD como recurso de integração e importância da realização de atividades interativas para manter a qualidade do curso.

O uso da abordagem pluralista possibilitou a identificação dos valores e necessidades a partir do envolvimento de grupos de egressos em relação aos aspectos considerados importantes na avaliação do curso realizado (processo formativo) e a consequente contribuição desses aspectos para a prática profisssional dos participantes (resultados esperados), contribuindo para a reflexão sobre práticas avaliativas aplicáveis à avaliação de programas educacionais nas instituições de ensino.

Ressalta-se que não se pretendeu esgotar todas as questões encontradas, as quais poderão ser aprofundadas em estudos futuros e com outras abordagens avaliativas. Destacamse como limitações enfrentadas durante a realização da pesquisa a dificuldade em reunir grupo de egressos, bem como a complexidade na condução da avaliação negociada, constituindo uma limitação da pesquisa o número reduzido de participantes nas sessões realizadas, o que não inviabiliza a sua aplicação com outras turmas do programa no âmbito da instituição pesquisada.

\section{REFERÊNCIAS}

ALMEIDA, M. B. Educação a distância na internet: abordagens e contribuições dos ambientes digitais de aprendizagem. Educação e Pesquisa, São Paulo, v. 29, n. 2, p-327340, jul/dez, 2003. Disponível em: http://www.scielo.br/pdf/ep/v29n2/a10v29n2.pdf $>$. Acesso em: 04 abr. 2015.

BAUER, Martin W.; GASKELL, George (org.). Pesquisa qualitativa com texto, imagem e som: um manual prático. Tradução de Pedrinho A. Guareschi. 5.ed. Rio de Janeiro: Vozes, 2008 .

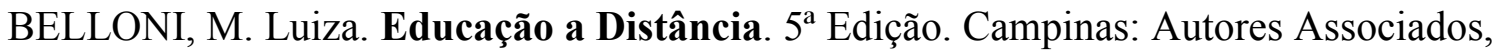
2008.

CAPES. Programa Nacional de Formação em Administração Pública - PNAP 2011.

Disponível em: $<$ http://www.capes.gov.br/educacao-a-distancia/pnap >. Acesso em: 05 mar. 2015. 
DEMARCO, D. J. Um Balanço do Programa Nacional de Formação em Administração Pública (PNAP) como estratégia de fortalecimento da gestão pública: o caso da Escola de Administração da UFRGS. In: IV Congresso de Gestão Pública - CONSAD, 2013. Anais. Brasília : UnB, 2013. p. 2-13.

DIAS SOBRINHO, José. Avaliação: políticas educacionais e reformas da educação superior teoria e experiências. São Paulo: Cortez, 2000.

DENZIN, Norman K; LINCOLN, Yvonna S. O Planejamento da Pesquisa Qualitativa: teorias e abordagens. Tradução: Sandra Regina Netz. 2. ed. Porto Alegre: Artmed, 2006, reimpressão 2010.

FERREIRA, R. A.; TENÓRIO, R. M. A construção de indicadores de qualidade no campo da avaliação educacional: um enfoque epistemológico. Revista Lusófona de Educação, Lisboa, v. 15, n. 5, p. 71-97, 2010.

FIGUEIREDO, M. Z. A; CHIARI, B. M; GOULART, B. N. G. Discurso do Sujeito Coletivo: uma breve introdução à ferramenta de pesquisa qualiquantitativa. Revista Distúrbios da Comunicação, São Paulo, v. 25, n. 1, p 129-136, 2013. Disponível em: < http://revistas.pucsp.br/index.php/dic/article/view/14931> . Acesso em: 26 jan. 2015.

GONDIM, S.M.G; FISCHER, T. O discurso, a análise de discurso e a metodologia do discurso do sujeito coletivo na gestão intercultural. Cadernos Gestão Social, Salvador, v.2, n.1, p.9-26, 2009. Disponível em:

$<$ http://www.periodicos.adm.ufba.br/index.php/cgs/article/view/75>. Acesso em: 26 jan.2015.

GONDIM, S. M. G.Grupos Focais como Técnica de Investigação Qualitativa: Desafios Metodológicos.Revista Paidéia. Cadernos de Psicologia e Educação. v.12, n.24, pp.149-161, 2003. Disponível em: <http://www.revistas.usp.br/paideia/article/view/46653/50409>. Acesso em: 26 jan.2015.

GROHMANN, M. Z; RISS, L. A; BATTISTELLA, L. F. Avaliação dos cursos do Programa Nacional de Formação de Administração Pública (PNAP): a visão dos discentes de uma instituição federal de ensino superior. Revista GUAL, Florianópolis, v. 7, n. 2, p. 175-197, maio 2014. Disponível em:

$<$ https://periodicos.ufsc.br/index.php/gual/article/view/1983-4535.2014v7n2p175>. Acesso em: 04 jan. 2015.

GUBA, E. G.; LINCOLN, Y. S. Avaliação de quarta geração. Campinas: Editora da Unicamp, 2011.

ISHIDA, J. S; STEFANO, S. R.; ANDRADE, S. Mara. Avaliação da Satisfação no Ensino de Pós a Distância: A Visão dos Tutores e Alunos do PNAP/UAB.2012. Avaliação, Campinas; SP, v. 18, n. 3, p. 749-772, nov. 2013. Disponível em:

$<$ http://www.scielo.br/scielo.php?script=sci_arttext\&pid=S1414-40772013000300012>.

Acesso em: 26 jan. 2015 
KANTORSKI, L.P. et al. Avaliação de quarta geração: contribuições metodológicas para avaliação de serviços de saúde mental. Interface - Comunic., Saude, Educ., v.13, n.31, p.343-55, out./dez. 2009. Disponível em:

$<$ http://www.scielo.br/scielo.php?script=sci_arttext\&pid=S1414-32832009000400009>. Acesso em: 22 fev. 2016.

KISHI, Kátia; PASSOS, Juliana. Especificidades da avaliação no ensino a distância. Com Ciência: Revista eletrônica de jornalismo científico, 2015, disponível em:

$<$ http://www.comciencia.br/comciencia/?section=8\&edicao=110\&id=1324>. Acesso em: 11 fev.2015.

KUO, Yu-Chun et al. A predictive study of student satisfaction in online education programs. The International Review of Research in Open and Distributed Learning, v. 14, n. 1, p. 16-39, 2013.

LEFÈVRE, F.; LEFÈVRE, A. M. C.; TEIXEIRA, J. J.V. (orgs.) O discurso do sujeito coletivo: uma nova abordagem metodológica em pesquisa qualitativa. Caxias do Sul: EDUCS, 2000.

LEFEVRE, A. M. C; CRESTANA, M. F; CORNETTA, V. K. A utilização da metododologia do discurso do sujeito coletivo na avaliação qualitativa dos cursos de especialização "Capacitação e Desenvolvimento de Recursos Humanos em SaúdeCADRHU", São Paulo - 2002. Saude soc. São Paulo, vol.12, n.2, p. 68-75, 2003. disponível em: < http://www.scielo.br/scielo.php?script=sci_arttext\&pid=S0104-12902003000200007>. Acesso em: 04 abr. 2016.

LEFÈVRE, F.; LEFÈVRE, A. M. C. Discurso do Sujeito Coletivo: Representações Sociais e Intervenções Comunicativas. Texto Contexto Enferm, Florianópolis, v. 23, n. 2, p. 505507, abr/jun, 2014. Disponível em: < http://www.scielo.br/pdf/tce/v23n2/pt_0104-0707-tce23-02-00502.pdf>. Acesso em: 26 abr. 2016.

MACHADO, G. R. Perfil do egresso da Universidade Federal do Rio Grande do Sul. Porto Alegre, 2010, 337 f. Tese (Doutorado em Educação). URGS, Porto Alegre, 2010. Orientadora: Prof ${ }^{a}$ Denise Balarine Cavalheiro Leite.

MARTINS, M. E; GARBIN, T. R. Mediação em fórum na EAD, uma postura que efetiva a educação colaborativa. ABED. In: Congresso 2011, Ouro Preto. Disponível em: $<$ http://www.abed.org.br/congresso2011/cd/52.pdf $>$. Acesso em: 02 maio 2016.

MEIRELLES, M. C. P; HYPOLITO, A. M; KANTORSKI, L. P. Avaliação de quarta geração: reciclagem de dados. J Nurs Health, Pelotas (RS); v. 2, n. 1, p. 63-74, jan/jun. 2012. Disponível em:

$<$ https://periodicos.ufpel.edu.br/ojs2/index.php/enfermagem/article/viewFile/3457/2842>. Acesso em 04 abr. 2016.

MONTEIRO DE FREITAS, A. A. S. Avaliação da Educação Superior no Brasil e Portugal Homogeneização ou Diferenciação? Avaliação, Campinas; Sorocaba, v. 17, n. 1, 
p. 119-136, mar. 2012. Disponível em: <http://www.scielo.br/pdf/aval/v17n1/a07v17n1.pdf>. Acesso em: 04 abr. 2016.

MORGAN, D. L. The focus group guidebook: Focus Group Kit1. Thousand Oaks: SAGE Publications, 1998.

MORAN, José Manuel. O que é educação a distância. Disponível em: $<$ http://www2.eca.usp.br/moran/wp-content/uploads/2013/12/dist.pdf >. Acesso em: 09 maio 2016.

PAIXÃO, Roberto Brazileiro. Avaliação de Impacto de Mestrados Profissionais: contribuições a partir da multidimensionalidade e da negociação. 2012. $323 \mathrm{f}$. Tese (Doutorado em Administração). UFBA, Salvador, 2012.

PAUL, Jean-Jacques. Acompanhamento de egressos do Ensino Superior: experiência brasileira e internacional. Caderno CRH, Salvador, v. 28, n. 74, p. 309-326. Maio/Ago. 2015.

ROTHEN, J. C. Ponto e Contraponto na Avaliação Institucional: análise dos documentos de implantação do Sinaes. Revista Educação: Teoria e Prática, Belo Horizonte, v. 15. n. 27, p. 119-137, 2006.

STAKE. Robert E. Program Evaluation, Particularly Responsive Evaluation. Center for Instructional Research and Curriculum Evaluation, University of Illinois. Keynote presentation at a conference on New Trends in Evaluation, at the Institute of Education at Göteborg University, Suécia, 1973.

TRAD, L. A. B. Grupos focais: conceitos, procedimentos e reflexões baseadas em experiências com o uso da técnica em pesquisas de saúde. Physis: Revista de Saúde Coletiva. Rio de Janeiro, v. 19, n. 3, 2009. Disponível em: <

http://www.scielo.br/scielo.php?script=sci_arttext\&pid=S0103-73312009000300013 >. Acesso em: 22 fev. 2016.

VERHINE, Robert E. Avaliação. Com Ciência SBPC/Labjor., 10 fev. 2015.. Disponível em: $<\mathrm{http}: / / \mathrm{www}$. comciencia.br/comciencia/?section $=8 \&$ tipo $=$ entrevista\&edicao $=110>$. Acesso em: 11 fev.2015. Entrevistado por Carolina Medeiros

WORTHEN, B. R.; SANDERS, J. R.; FITZPATRICK, J. L. Avaliação de programas: concepções e práticas. São Paulo: Editora Gente, 2004. 